\title{
Statistical Analysis, Clinical Symptoms and Preventive Measures of College students' Common Diseases
}

\author{
Hongjun Teng ${ }^{1, a^{*}}$, Zhenbo Bao ${ }^{2, b}$ and Fan Yang ${ }^{2, c}$ \\ ${ }^{1}$ Clinic, Tianjin Agricultural University, Tianjin, China, 300384 \\ ${ }^{2}$ Engineering and Technology College, Tianjin Agricultural University, Tianjin, China, 300384 \\ a*hongjun-teng@163.com, bbaozhenbo@sohu.com, cfanyang20062800@126.com
}

Keywords: College students; Common diseases; Preventive Measures; Clinical Symptoms

\begin{abstract}
College students shoulder the heavy responsibility of building the country, which are the future of the motherland. College students' health has a profound influence on society. Due to the lack of health knowledge and the influence of some unhealthy lifestyles, college students are prone to some diseases. In the outpatient treatment work, from September 2016 to January 2018, through the statistics of common diseases of college students in the Tianjin Agricultural University, the types, numbers, and proportion of college students' common diseases are counted. The clinical symptoms of common diseases are summarized, and the corresponding preventive measures are proposed. College students should arrange their own schedules scientifically and actively participate in physical exercise. School educators should strengthen the health education of students, reduce the incidence of college students' common diseases, and improve the physical and mental health of college students.
\end{abstract}

\section{Introduction}

The age of college students in ordinary universities is generally 17-25 years old, and they are tending to grow steadily from the period of youth development. The physiological functions and psychological adaptability of college students in this age group are also basically mature, healthy, vigorous, and the body has strong immunity. College students are an important resource for scientific and technological progress and social development. College students shoulder the heavy responsibility of building the country and it is the future of the motherland. College students' physical health has a profound influence on society. However, due to the lack of health knowledge and the uncontrolled adjustment of some unhealthy lifestyle influences and emotional psychology, it is easy to cause certain diseases and accidental injuries. Promoting the healthy growth of college students is the starting point and destination of all the work in the school. It is an important task for higher education to continuously improve the physical health of college students. I have been engaged in the diagnosis and treatment of comprehensive out-patient clinics, health care, and health education for more than 10 years. I have deeply realized that through health education, college students can master the knowledge of disease prevention and the reduction of accidental injuries. It is a strong guarantee for college students to live healthily in school and successfully complete their studies. From September 2016 to January 2018, through the statistics of college students' common diseases in the Tianjin Agricultural University, the distribution of common diseases and clinical symptoms of college students are summarized, and references for better prevention, health care and health education are provided [1,2].

\section{Statistical Analysis of College Students' Common Diseases in Tianjin Agricultural College}

In the outpatient treatment work, the statistics of college students attending the medical office of the Tianjin Agricultural University in September 2016 and January 2018 were counted, with a total of 1,639 visits as the objects of analysis, recipients are not included in the statistics. The age of university students attending the clinic is 18-25 years old. College students' common diseases include colds, upper respiratory tract infections (pharyngitis, tonsils, etc.), fire, sprains, skin allergies, bronchitis, gastroenteritis, toothache, stomachache, eye fatigue, conjunctivitis, headache, dizziness, hypertension 
and hypotension, otitis media, beriberi, etc. 15 species, the distribution of the common diseases and their proportions are shown in Table $1[3,4]$.

Table 1 The distribution and proportion of college students' common diseases in Tianjin Agricultural University

\begin{tabular}{|c|c|c|c|}
\hline No. & Common diseases & Cases & Proportion[\%] \\
\hline 1 & Cold & 476 & 29.04 \\
\hline 2 & Upper respiratory tract infections (pharyngitis, tonsils, etc.) & 280 & 17.08 \\
\hline 3 & Fire & 175 & 10.68 \\
\hline 4 & Sprain & 175 & 10.68 \\
\hline 5 & Skin allergy & 151 & 9.21 \\
\hline 6 & Bronchitis & 77 & 4.70 \\
\hline 7 & Gastroenteritis & 70 & 4.27 \\
\hline 8 & Toothache & 65 & 3.97 \\
\hline 9 & Stomachache & 46 & 2.81 \\
\hline 10 & Eye fatigue & 33 & 2.01 \\
\hline 11 & Conjunctivitis & 32 & 1.95 \\
\hline 12 & Headache, dizziness, hypertension and hypotension & 27 & 1.65 \\
\hline 13 & Dysmenorrhea & 13 & 0.79 \\
\hline 14 & Otitis media & 11 & 0.67 \\
\hline 15 & Beriberi & 1639 & 0.49 \\
\hline Total & & & 100 \\
\hline
\end{tabular}

The 12 common diseases with a high proportion of distribution are cold, upper respiratory tract infections (pharyngitis, tonsils, etc.), fire, sprain, skin allergy, bronchitis, gastroenteritis, toothache, stomachache, eye fatigue, conjunctivitis, headache, dizziness, hypertension and hypotension, and their distribution proportions are shown in Fig 1.

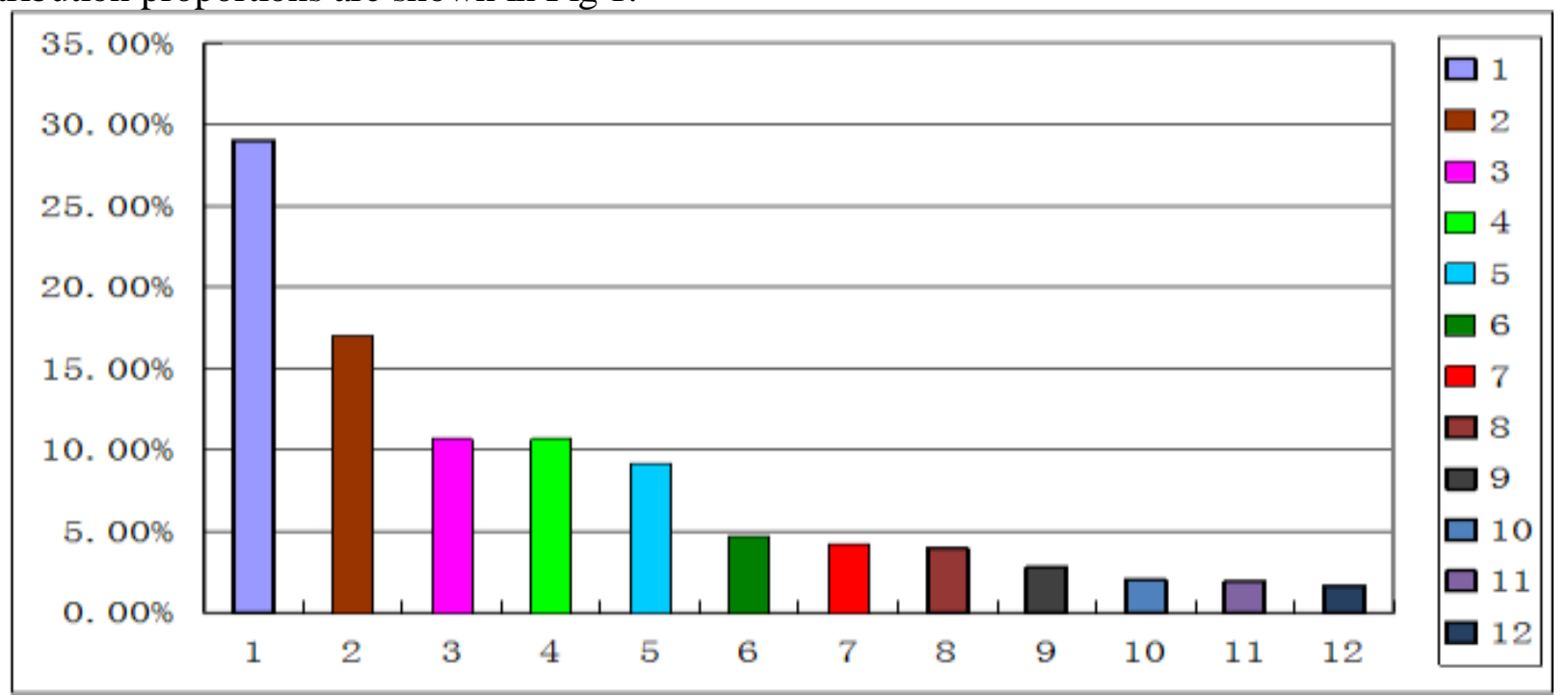

1.Cold 2.Upper respiratory tract infections (pharyngitis, tonsils, etc.) 3.Fire 4.Sprain 5.Skin allergy 6.Bronchitis 7.Gastroenteritis 8.Toothache 9.Stomachache 10.Eye fatigue 11.Conjunctivitis 12.Headache,dizziness, hypertension and hypotension

Figure 1. Distribution bar of 12 college students' common diseases in Tianjin Agricultural University 


\section{Main Symptoms and Preventive Measures of College Students' Common Diseases in Tianjin Agricultural University}

It is of great practical significance to reduce the occurrence of common diseases and improve the physical and mental health of college students by summarizing the clinical symptom features of college students' common diseases and putting forward preventive measures. The main symptom features and preventive measures of 12 college students' common diseases are summarized as shown in Table 2 [5, $6]$.

Table 2 Main clinical symptoms and preventive measures of college students' common diseases in Tianjin Agricultural University

\begin{tabular}{|c|c|c|}
\hline $\begin{array}{c}\text { Common } \\
\text { diseases }\end{array}$ & Clinical symptoms & Preventive measures \\
\hline Cold & $\begin{array}{l}\text { Chills, stuffy nose, runny nose, } \\
\text { cough, fever, sneezing, sore } \\
\text { throat, headache, body aches, } \\
\text { fatigue, fatigue, etc. }\end{array}$ & $\begin{array}{l}\text { More exercise, enhance physical fitness. often } \\
\text { wash hands. Do not tired, avoid stress and } \\
\text { worries, do not stay up all night, and improve } \\
\text { immunity. Wear more clothes in the winter, } \\
\text { keep warm, and avoid places that are crowded. }\end{array}$ \\
\hline $\begin{array}{l}\text { Upper } \\
\text { respiratory } \\
\text { tract infections } \\
\text { (pharyngitis, } \\
\text { tonsils, etc.) }\end{array}$ & $\begin{array}{l}\text { Clinical symptoms of } \\
\text { pharyngitis: The main symptom } \\
\text { of pharyngitis is pharyngeal } \\
\text { discomfort, dry, itchy, } \\
\text { distended, secretions and } \\
\text { burning pain, easy to do evil, } \\
\text { have foreign body sensation. } \\
\text { Clinical symptoms of tonsillitis: } \\
\text { Chills, fever, headaches, the } \\
\text { throat is dry, there is a sense of } \\
\text { blockage, secretions are sticky, it } \\
\text { is not easy to cough up, bad } \\
\text { breath and so on. }\end{array}$ & $\begin{array}{l}\text { Preventive measures of pharyngitis: it is suggest } \\
\text { drinking plenty of water, avoiding excessive use } \\
\text { of phlegm, diet drink more cool throat drink and } \\
\text { eating fruit, pay attention to moisture. } \\
\text { Preventive measures of tonsils: Usually have } \\
\text { regular physical exercise, enhance physical } \\
\text { fitness, and improve the body's resistance to } \\
\text { disease. Regular life, avoid overwork. Pay } \\
\text { attention to oral hygiene, quit alcohol and } \\
\text { tobacco. Diet should be light, do not eat spicy } \\
\text { food. }\end{array}$ \\
\hline Fire & $\begin{array}{l}\text { Eyes red and swollen, mouth } \\
\text { erosion, yellow urine, toothache, } \\
\text { sore throat, etc.. }\end{array}$ & $\begin{array}{l}\text { Usually pay attention to the combination of } \\
\text { labor and leisure, eat less spicy fried and other } \\
\text { hot foods. }\end{array}$ \\
\hline Sprain & $\begin{array}{l}\text { Pain and swelling in the } \\
\text { damaged area and limited joint } \\
\text { activity, often in the waist, ankle, } \\
\text { knee, shoulder, wrist, elbow, hip } \\
\text { and other parts. }\end{array}$ & $\begin{array}{l}\text { Exercise training methods should be reasonable, } \\
\text { preparation activities should be sufficient, pay } \\
\text { attention to relaxed spacing, prevent local heavy } \\
\text { burden, and strengthen muscle strength } \\
\text { exercises in vulnerable parts. }\end{array}$ \\
\hline Skin allergy & $\begin{array}{l}\text { The surface of the skin is dry, } \\
\text { red and swollen, spots, itching, } \\
\text { peeling and allergic dermatitis, } \\
\text { dark sores, etc.. }\end{array}$ & $\begin{array}{l}\text { Wash face water not too hot, bath and face } \\
\text { separated, avoid barbecue, spicy, fried and other } \\
\text { foods, and keep the air moist, as far as possible } \\
\text { to sun protection. }\end{array}$ \\
\hline Bronchitis & $\begin{array}{l}\text { Long-term cough, phlegm, or } \\
\text { accompanied by wheezing are } \\
\text { the main characteristics. }\end{array}$ & $\begin{array}{l}\text { The food is forbidden to eat hot, fishy taste, } \\
\text { should exercise the body properly, and } \\
\text { strengthen the body disease resistance ability. }\end{array}$ \\
\hline Gastroenteritis & $\begin{array}{l}\text { Abglum distension, abdominal } \\
\text { pain, diarrhea, intermittent } \\
\text { abdominal pain. }\end{array}$ & $\begin{array}{l}\text { Regular diets, to be regular and quantitative, do } \\
\text { not overeat. Chew slowly, eat less irritating } \\
\text { food, and keep the spirit happy. }\end{array}$ \\
\hline Toothache & $\begin{array}{l}\text { The gums are red and swollen, } \\
\text { soft, prone to bleeding and pain. } \\
\text { Gum itching, discomfort, hot }\end{array}$ & $\begin{array}{l}\text { Pay attention to oral hygiene. Develop the habit } \\
\text { of brushing teeth sooner or later, gargle after } \\
\text { meal. Discover cavities and treat them promptly. }\end{array}$ \\
\hline
\end{tabular}




\begin{tabular}{|c|c|c|}
\hline & $\begin{array}{l}\text { and cold stimulate pain, swollen } \\
\text { cheeks, bad breath and so on. }\end{array}$ & $\begin{array}{l}\text { Do not eat sugar, biscuits and other food before } \\
\text { going to bed. Should eat more Qingwei Huo and } \\
\text { Qinggan fire food. Avoid irritation and anger. } \\
\text { Keep your stool open and smooth. Eat less sour, } \\
\text { too cold, overheated food. }\end{array}$ \\
\hline Stomachache & $\begin{array}{l}\text { Hiccups, flatulence, chest } \\
\text { tightness, nausea, vomiting, } \\
\text { diarrhea, vomiting acid, hiccups, } \\
\text { fasting pain, and fullness and } \\
\text { hunger. }\end{array}$ & $\begin{array}{l}\text { Eat more porridge on the diet, and avoid } \\
\text { irritating foods, acidic foods and acidic fruits. } \\
\text { Foods those are prone to gas production, or } \\
\text { irritating foods. Eat less fried foods. Eat less } \\
\text { pickled foods and eat less cold food. }\end{array}$ \\
\hline Eye fatigue & $\begin{array}{l}\text { Ophthalmic dryness, eye } \\
\text { astringent, eye acid distension, } \\
\text { blurred or even visual acuity, } \\
\text { accompanied by symptoms such } \\
\text { as neck, shoulder and other } \\
\text { corresponding parts of pain. }\end{array}$ & $\begin{array}{l}\text { Pay attention to eye care in daily life to avoid dry } \\
\text { eyes. Use eyes properly, pay attention to mental } \\
\text { relaxation, and take proper rest when eyes are } \\
\text { tired. Televisions and computers should not be } \\
\text { placed above the level of the eyes. The computer } \\
\text { should have radiation screen protection and so } \\
\text { on. }\end{array}$ \\
\hline Conjunctivitis & $\begin{array}{l}\text { Eye redness, foreign body } \\
\text { sensation, burning sensation, } \\
\text { heavy eyelids, swollen eyelids, } \\
\text { increased eye secretions, tears, } \\
\text { mild photophobia, visual } \\
\text { impairment. }\end{array}$ & $\begin{array}{l}\text { Wash hands frequently and avoid kneading } \\
\text { eyes. Wash face with running water, towels, } \\
\text { handkerchief and other items should be } \\
\text { separated from others, and often cleaning and } \\
\text { disinfection. Wear protective eyeglasses when } \\
\text { the environment is windy. }\end{array}$ \\
\hline \multirow{4}{*}{$\begin{array}{l}\text { Headache, } \\
\text { dizziness, } \\
\text { hypertension } \\
\text { and } \\
\text { hypotension }\end{array}$} & $\begin{array}{l}\text { Headache: Skyrocketing, } \\
\text { top-heavy, unable to lift the } \\
\text { spirit, before the black (feeling } \\
\text { blurred vision, or even } \\
\text { temporarily lost consciousness), } \\
\text { nausea, boredom, loss of } \\
\text { appetite or even vomiting. }\end{array}$ & $\begin{array}{l}\text { Headache: In terms of diet, eat less meal and eat } \\
\text { less greasy food. }\end{array}$ \\
\hline & $\begin{array}{l}\text { Dizziness: Headache, nausea, } \\
\text { vomiting, paleness, sweating, } \\
\text { palpitations, transient vision } \\
\text { impairment, eye pain, retinal } \\
\text { hemorrhage. }\end{array}$ & $\begin{array}{l}\text { Dizziness: Eat more fruits and vegetables rich in } \\
\text { cellulose and vitamins in the diet. Diets should } \\
\text { be diversified, omnivorous grains. Food that is } \\
\text { easy to digest and has a softer texture. Should } \\
\text { refrain from eating or eat less irritating diet. Do } \\
\text { not eat greasy, cold and hot food. }\end{array}$ \\
\hline & $\begin{array}{l}\text { Hypertension: Headache, } \\
\text { dizziness, tinnitus, palpitation, } \\
\text { shortness of breath, insomnia, } \\
\text { numbness of limbs, etc. }\end{array}$ & $\begin{array}{l}\text { Reduce salt intake, limit alcohol intake, eat more } \\
\text { fruits containing potassium, ingest enough } \\
\text { calcium, and eat less fat meat and animal internal } \\
\text { organs. Multiple exercise. Lighten your stress } \\
\text { levels and stay in a good mood. The bath water } \\
\text { should not be too cold. }\end{array}$ \\
\hline & $\begin{array}{l}\text { Hypotension: } \\
\text { headache, loss of appetite, } \\
\text { fatigue, paleness, indigestion, } \\
\text { etc.. }\end{array}$ & $\begin{array}{l}\text { When sleeping, pillows should be high. Do not } \\
\text { move too quickly when standing up or flexing or } \\
\text { stretching. Bath water temperature should not } \\
\text { be too cold. Drink plenty of water every day. Do } \\
\text { not stand too long in a hot or oxygen-deficient } \\
\text { environment. }\end{array}$ \\
\hline
\end{tabular}




\section{Summary}

Through the statistical analysis and clinical practice summary of the common diseases of college students in Tianjin Agricultural University, the common cause of college students' common diseases is that college students have some bad habits, lack of correct understanding and prevention knowledge of diseases. College students themselves should cultivate good living habits, scientific arrangements for the rest of the time, labor and leisure combination, to ensure adequate sleep. Schools can make some measures to help students to arrange the rest time. College students should take part in physical exercise every day and often take part in outdoor activities and recreational activities. Scientifically arrange meals, eat more fresh foods, avoid partial eclipses, eat less or not eat junk food, don't eat supplements, do not blindly lose weight, and prevent malnutrition and obesity. As health educators, should take the initiative to strengthen college students' health education and pay attention to the combination of prevention. If conditions permit, can establish student health records, timely control and eliminate factors that affect health, and reduce the incidence of college students' common diseases [7, 8].

\section{Acknowledgements}

This work was financially supported by the Project of Tianjin Agricultural University Education and Teaching Reform Research (2016-A-04).

\section{References}

[1] W.Y. Yan, X.M. Jia: For all Health, Vol. 10 (2016) No.15, p.8.

[2] X.C. Sun: China Medical Engineering, Vol. 19 (2011) No.12, p.149-150.

[3] W.J. Liu: Journal of Guangdong University of Petrochemical Technology, Vol. 23 (2013) No.5, p.35-37.

[4] Z,H, Lu: Journal of Qiqihar University of Medical, Vol. 36 (2015) No.11, p.1664-1665.

[5] P.H. Wang: Journal of Anhui Institute of Education, Vol. 25 (2007) No.6, p.89-92.

[6] Y.H. Feng, M.Y. Wu, H.L. Chen: Journal Traditional Medicine Management, Vol. 24 (2016) No.10, p.167-169.

[7] S.M. Sun: Chin J Sch Health, Vol. 35 (2014) No.11, p.1739-1741.

[8] Q.T. Wu, J.W. Gan: Health Medicine Research and Practice, Vol. 12 (2015) No.5, p.86-88. 